\title{
Hydatid disease of bone: a dangerous crippling disease
}

\author{
Dinesh Harvey Raj, Prafulla Kumar Dash
}

Department of Radiodiagnosis, CMIIL-SCB Medical MRI

Centre, Cuttack, Odisha, India

\section{Correspondence to} Dr Prafulla Kumar Dash, harveymdrd.1987@gmail.com

Accepted 7 August 2015
CrossMark

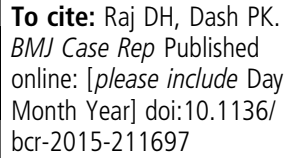
BMJ Case Rep Published online: [please include Day Month Year] doi:10.1136/ bcr-2015-211697

\section{DESCRIPTION}

A 40-year-old man presented with severe pelvic and right hip joint pain for the past 5 years, which was insidious in onset and progressive, resulting in the patient being wheelchair-bound. He also had a history of liver surgery, which was performed 20 years prior, and for which the documentary details were lost. There was no history of fever, trauma, previous tuberculosis or bone tumours. Routine blood investigations were unremarkable. Chest X-ray was normal. X-ray of the pelvis, anteroposterior view, revealed multiple expansile lytic lesions involving the right ilium, right ischium and right pubis with involvement of the right ala of the sacrum, right hip joint, and right head and neck of the femur (figure 1). CT of the pelvis demonstrated the aforementioned findings along with extensive bone remodelling changes and disuse atrophy of the right gluteal muscles, and a three-dimensional volumetric reconstruction image of pelvic bones and femur also clearly demonstrated the findings aforementioned (figure 2). The main differentials considered were tuberculosis, osteomyelitis and osteosarcoma. We proceeded with incisional biopsy of the lesion from the right iliac bone but, to our surprise, the histopathology

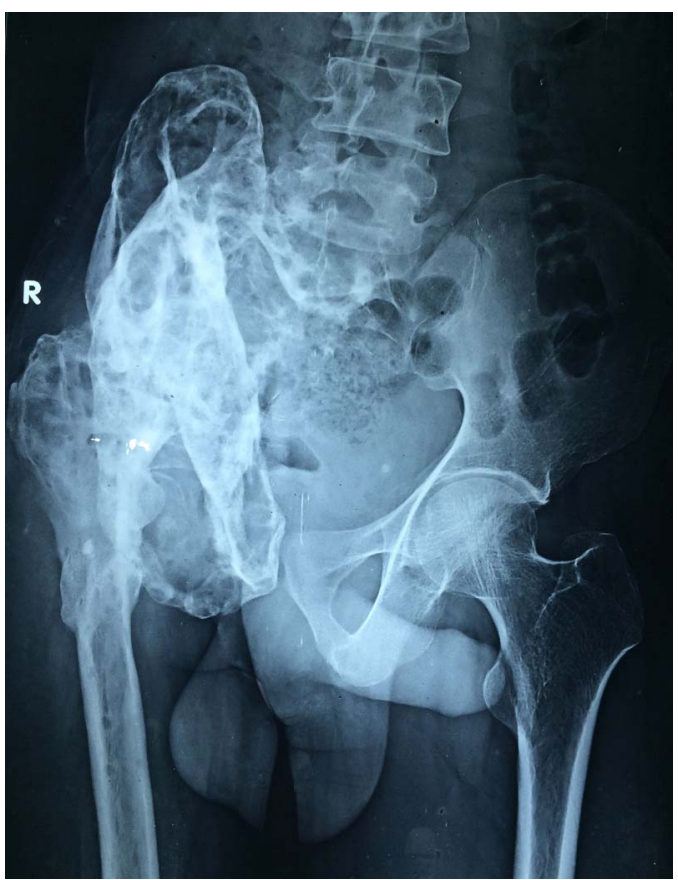

Figure 1 X-ray of the pelvis, anteroposterior view, revealing multiple expansile lytic lesions involving the right ilium, right ischium and right pubis, with involvement of the right ala of the sacrum, right hip joint, and right head and neck of femur.

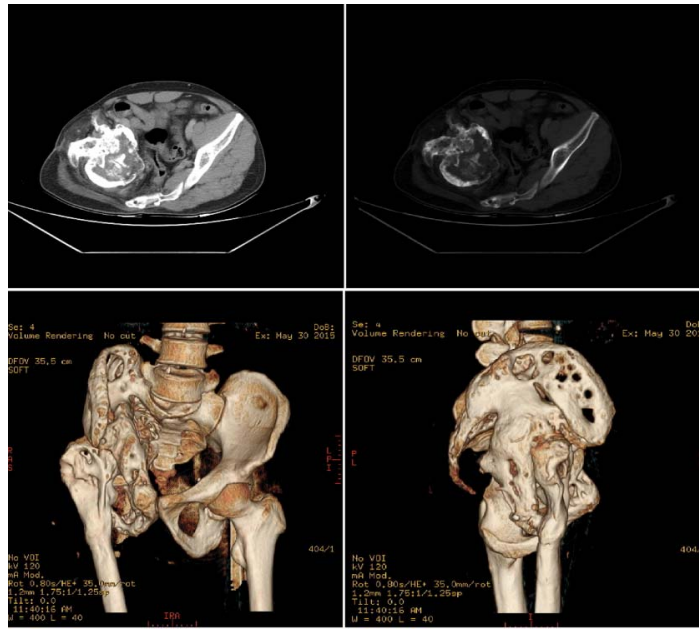

Figure 2 CT of the pelvis in abdominal and bone windows demonstrating multiple expansile destructive lytic lesions along with extensive bone remodelling changes of the right pelvic bones, right femur, right ala of sacrum and disuse atrophy of the right gluteal muscles. A three-dimensional volumetric reconstruction image of pelvic bones and femur showing features of hydatid disease of bone.

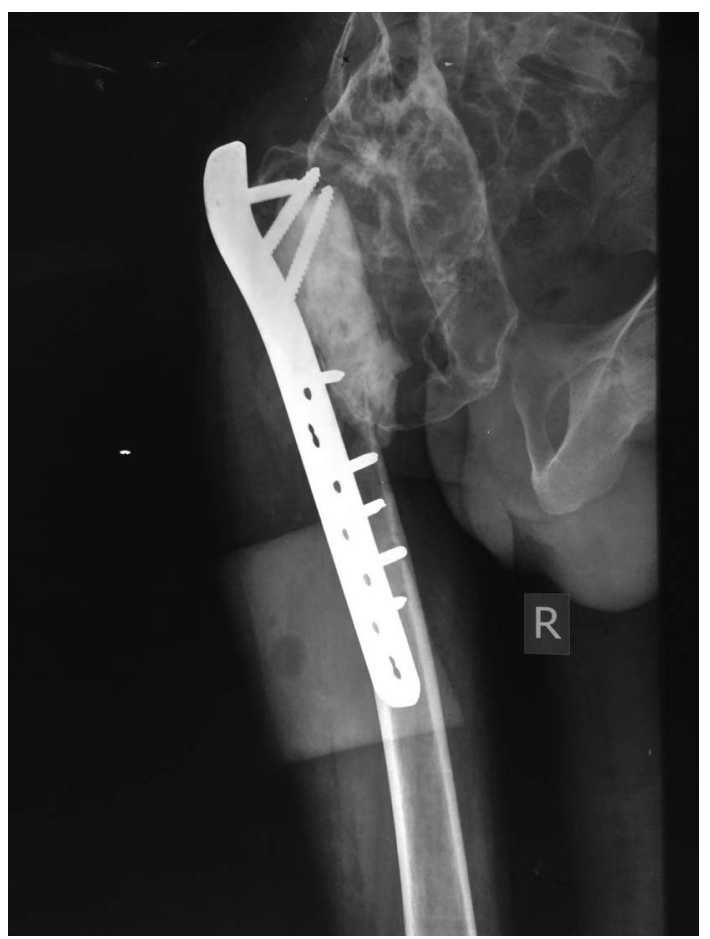

Figure 3 X-ray of the pelvis, anteroposterior view: postoperative picture showing internal fixation with plate and screws in right femur after local excision and curettage. 
indicated hydatid disease. Albendazole and praziquantel, antihelminthic drugs, at doses of 10 and $25 \mathrm{mg} / \mathrm{kg}$, respectively, were started preoperatively, and wide local excision and curettage with internal fixation by plate and screws were performed in the right femur (figure 3); the patient has continued on the same antihelminthic drugs, to date. The pelvic lesions were asymptomatic, so we decided not to surgically treat them, as our primary concern was to get the patient ambulant. The patient is currently ambulant with crutches and is asymptomatic.

Hydatid disease is caused by Echinococcus granulosis and may develop in almost any part of the body. Bone localisation is

\section{Learning points}

- In endemic areas, hydatid disease of bone, although extremely rare, should be considered as a differential diagnosis for destructive expansile lytic lesions.

- Early diagnosis of the disease and extensive resection of the affected bone gives a favourable outcome.

- Recurrence of this disease is very common, so long-term follow-up is important. rare, comprising $0.5-2.5 \%$ of all human hydatidosis. About $50 \%$ of cases of bone hydatid disease affect the spine. The second most frequent location is the pelvis $(21 \%)$, followed by the femur (16\%) and tibia (10\%). ${ }^{1}$ Diagnosis is primarily based on X-ray and CT scan findings. X-ray findings include monolocular, bilocular or multilocular cysts. They are characterised by oval or polycyclic non-specific lacunae of variable sizes. Progression of the disease takes place in two forms: formation of diverticuli and exogenous vesiculation. ${ }^{2} 3$ Surgery, wide local resection and antihelminthic therapy are the mainstay of management; recurrence is very common.

Competing interests None declared.

Patient consent Obtained.

Provenance and peer review Not commissioned; externally peer reviewed.

\section{REFERENCES}

1 Sapkas GS, Stathakopoulos DP, Babis GC, et al. Hydatid disease of bones and joints. 8 cases followed for 4-16 years. Acta Orthop Scand 1998;69:89-94.

2 Markakis P, Markaki S, Prevedorou D, et al. Echinococcosis of bone: clinico-laboratory findings and differential diagnostic problems. Arch Anat Cytol Pathol 1990;38:92-4.

3 Saidi F. Hydatid cysts of bone. In: Surgery of hydatid disease. London: WB Saunders, 1976:135-8.

Copyright 2015 BMJ Publishing Group. All rights reserved. For permission to reuse any of this content visit

http://group.bmj.com/group/rights-licensing/permissions.

BMJ Case Report Fellows may re-use this article for personal use and teaching without any further permission.

Become a Fellow of BMJ Case Reports today and you can:

- Submit as many cases as you like

- Enjoy fast sympathetic peer review and rapid publication of accepted articles

- Access all the published articles

- Re-use any of the published material for personal use and teaching without further permission

For information on Institutional Fellowships contact consortiasales@bmjgroup.com

Visit casereports.bmj.com for more articles like this and to become a Fellow 